Open Access

\title{
Highly divergent ancient gene families in metagenomic samples are compatible with additional divisions of life
}

Philippe Lopez ${ }^{1 *}$, Sébastien Halary ${ }^{2}$ and Eric Bapteste ${ }^{1}$

\begin{abstract}
Background: Microbial genetic diversity is often investigated via the comparison of relatively similar 165 molecules through multiple alignments between reference sequences and novel environmental samples using phylogenetic trees, direct BLAST matches, or phylotypes counts. However, are we missing novel lineages in the microbial dark universe by relying on standard phylogenetic and BLAST methods? If so, how can we probe that universe using alternative approaches? We performed a novel type of multi-marker analysis of genetic diversity exploiting the topology of inclusive sequence similarity networks.
\end{abstract}

Results: Our protocol identified 86 ancient gene families, well distributed and rarely transferred across the 3 domains of life, and retrieved their environmental homologs among 10 million predicted ORFs from human gut samples and other metagenomic projects. Numerous highly divergent environmental homologs were observed in gut samples, although the most divergent genes were over-represented in non-gut environments. In our networks, most divergent environmental genes grouped exclusively with uncultured relatives, in maximal cliques. Sequences within these groups were under strong purifying selection and presented a range of genetic variation comparable to that of a prokaryotic domain.

Conclusions: Many genes families included environmental homologs that were highly divergent from cultured homologs: in 79 gene families (including 18 ribosomal proteins), Bacteria and Archaea were less divergent than some groups of environmental sequences were to any cultured or viral homologs. Moreover, some groups of environmental homologs branched very deeply in phylogenetic trees of life, when they were not too divergent to be aligned. These results underline how limited our understanding of the most diverse elements of the microbial world remains, and encourage a deeper exploration of natural communities and their genetic resources, hinting at the possibility that still unknown yet major divisions of life have yet to be discovered.

Reviewers: This article was reviewed by Eugene Koonin, William Martin and James Mclnerney.

Keywords: Microbiology, Metagenomics, Comparative analysis, Networks, Environmental diversity

\footnotetext{
*Correspondence: philippe.lopez@upmc.fr

'Team 'Adaptation, Integration, Reticulation, Evolution' - UMR CNRS 7138

Evolution Paris Seine - Institut de Biologie Paris Seine - Université Pierre et

Marie Curie, 7 quai St Bernard, 75005 Paris, France

Full list of author information is available at the end of the article
} 


\section{Open peer review}

Reviewed by Eugene Koonin, William Martin and James McInerney. For the full reviews, please go to the Reviewers' comments section.

\section{Background}

The study of environmental sequences has repeatedly shown evidence for novel divisions of cellular lineages. In particular, the number of bacterial and archaeal lineages in the ribosomal tree has continued growing since Woese published a first tree of life in 1987 [1, 2]. Importantly, these environmental sequences are rarely identical to sequences from cultured organisms, which are estimated to represent less than $1 \%$ of species diversity [3]. Many environmental sequences resemble other environmental sequences, and have no hits in homology searches outside the sequences from their own metagenome $[4,5]$. These observations suggest that phylogenetic diversity inferences based on cultivation studies are still limited [1, 6], and that a vast "microbiological dark matter" still deserves to be critically analyzed $[7,8]$.

There has been constant progress on that front. In 1998, new division-level bacterial lineages were reported in a Yellowstone hot spring, the Obsidian Pool [1]. Evidence was obtained from small subunit rRNA genes by restriction fragment length polymorphism. Thirty percent of the genes were unaffiliated with recognized bacterial divisions, amounting to 12 novel candidate divisions. The majority of the environmental sequences produced in that study were only modestly related to known ribosomal sequences (showing less than $85 \%$ identity with known sequences). Two of these novel divisions presented more than two representatives, giving a better sense of the significant phylogenetic depth of these lineages. Likewise, in 2005, two novel bacterial divisions were described in an anaerobic wastewater plant[2]. Again, evidence came from the analysis of $16 \mathrm{~S}$ rRNA genes. At that time already, a third of the known bacterial divisions had no cultured representatives and were exclusively known through their detection via ribosomal sequences and universal primers [2]. Recently Brown and Luef reported the existence of CPR, a basal group comprising over $15 \%$ of the bacterial domain and resisting cultivation because of their extremely small size, limited number of ribosomes, and their metabolic dependence coupled with the presence of pilus-like structures enabling compensatory interactions $[6,9]$. Moreover the bacterial domain was not the only one in which repeated findings of novel divergent groups occurred (see also [10-15]). Phylogenetic analyses of environmental sequences also hinted at the existence of previously unobserved archaea [16-18] and eukaryotic lineages [19-22].
The growing use of next-generation sequencing further enhanced the depth of the environmental sampling, amplifying this general trend of discovery of novel lineages. As a result, uncultivated microbes detected in SSU rRNA surveys have quadrupled since 2007, reaching > $85 \%$ of the known microbial diversity reported to date [23]. Lately, this pattern of recurrent discovery of novel microbial diversity has even suggested the existence of novel higher level groups, such as novel candidate domains of life. The key observation for this was the discovery of environmental sequences appearing highly distantly related to sequences from cultured organisms, as introduced in the pioneering work by Wu et al. [24].

All these results prompted the search for novel reference genomes outside the usual cultured prokaryotic and viral phyla $[6,9,23,25]$. In 2012, the genomes of two unusual ultrasmall free-living uncultivated Archaea from a hypersaline Australian lake were de novo assembled [26]. These environmental taxa presented distinctive metabolic features and amino-acid composition with respect to other archaea, and $60 \%$ of their predicted proteins could not be phylogenetically assigned. Their $16 \mathrm{~S}$ rRNA was only $68 \%$ to $75 \%$ similar to cultured representatives of haloarchaea. Phylogenetic analyses of multiple markers managed to position them as members of a new major class, called Nanohaloarchaea. Similarly, in 2013, two giant viruses, Pandoravirus salinus and Pandoravirus dulcis, were discovered off the coast of central Chile and in a freshwater pond near Melbourne[25]. These enormous viruses proved highly unusual: only $7 \%$ of their genes showed homology to known sequences (with an average of only $38 \%$ similarity). These genomes were also completely devoid of capsid proteins. Evidence that unknown life forms populated the microbial world, i.e. microbes still unsequenced to date, including possibly some microbial dark matter (e.g. microbes that are especially difficult to grow in lab cultures) was ever growing.

Interestingly, just like many other environments, the human microbiome also presented an exciting share of unknown organisms [27, 28]. Comparing predicted genes from over 1 million shotgun reads to an extended reference database, Kurokawa et al. found that the sequences from the majority of gut microbes were highly divergent from previously known sequences[29]. Most of the organisms represented by these sequences were uncharacterized at the genus level. In 2010, Qin et al. investigated the diversity of fecal samples of 124 European adults and reported that only $31-48.8 \%$ of the reads from their studies (plus those from two former studies with comparable methodology but smaller sampling size) could be assigned to 194 public human gut bacterial genomes, while 7.6-21.2 \% could be assigned to the bacterial genomes from Genbank [30]. Numerous completely novel gene families without known functions, 
amounting together to three quarters of the gene families of the gut microbiome, were also reported [30]. One year later, Arumugam et al. analyzed metagenomes from 39 individuals and estimated that around $16.5 \%$ of the reads were likely to belong to yet unknown genera [31]. Finally, in 2012, the use of 212 different culture conditions revealed novel species and genera in the gut microbiome, including the largest bacterial genome and the largest virus reported in that environment, demonstrating that metagenomic studies still underestimate microbial diversity within the gut [8]. Thus, wherever one looks in nature - from hot springs to human guts-, novel microbial lineages from various taxonomic levels are being discovered through environmental sequencing.

However, a general question remains to be addressed: are we missing novel lineages in the microbial dark universe by relying on standard phylogenetic and BLAST methods? If so, how can we probe that universe using alternative sensitive approaches? Indeed, studies of microbial dark matter using metagenomic data raise significant methodological challenges for comparative analyses. A first difficulty comes from the size of the dataset. For instance, in 2012, Lynch et al. devised a strategy to analyze 6.5 million assembled paired-end Illumina reads of $16 \mathrm{~S}$ rRNA from Arctic tundra soil samples [32], in which they found 3 very divergent bacterial lineages. To handle this large amount of data, the authors relied first on sequence similarity networks. Nodes in these networks corresponded to abundant environmental $16 \mathrm{~S}$ rRNA sequences and reference sequences from a database with 2,000,000 curated assigned sequences, connected by edges when they presented $>90 \%$ identity and matched over $>=80 \%$ of their hit length. In such networks, candidate new lineages are typically unconnected to reference sequences, because they are highly divergent [32]. This study had a strong methodological implication: novel comparative strategies and tools are critical for the screening of the microbial dark matter, because reconstructing a tree of every $16 \mathrm{~S}$ rRNA sequences was no longer a tractable default option (or at least became a real challenge).

Comparative strategies targeting novel lineages however need to be designed with the specific goal of enhancing the exploratory power of microbial diversity analyses, which could also benefit microbial dark matter analyses. Thus, a second difficulty in analyzing microbial diversity comes from the very nature of novel lineages, which are by definition very divergent from known lineages. Indeed, divergent $16 \mathrm{~S}$ ribosomal RNA gene sequences evade detection in typical cultivationindependent surveys [9]. Similarly, the most divergent environmental sequences can hardly be included in comparative phylogenetic analyses, because divergent environmental sequences and sequences from cultured organisms often fail to align sufficiently well when introduced together in multiple sequence alignments. Therefore, the usual phylogenetic approaches, even though they appear very promising for species assignation, might impose methodological constraints that are too restrictive to serve as first tools of choice for exploratory searches of highly divergent environmental sequences. For methodological reasons, it might be difficult, if not practically impossible, to use truly divergent genes from truly divergent life forms, such as very divergent groups or eventual additional domains of Life, to reconstruct phylogenetic trees that simultaneously contain both novel divergent lineages branching outside (rather than within) the three domains of Life and sequences from Archaea, Bacteria and Eukaryotes. Problematically, most intriguing environmental sequences might then tend to be discarded in the first steps of classic comparative analyses of genetic diversity, making it less likely that very divergent lineages could be easily detected by these approaches [9].

Consequently, to show that the microbial dark universe could be probed by alternative methods, we developed a novel protocol for the exploitation of huge numbers of molecular sequences in exploratory diversity surveys. We designed a multi-marker sampling strategy, relying on sequence similarity network to identify (i) well-distributed gene families in cultured prokaryotes and (ii) their distant environmental homologs, characterized by their topological distance to known sequences in these graphs and their significant sequence divergence ( $>40 \%$ ) from their closest published homolog present in the NCBI database in July 2013. We applied these tools to environmental samples, with a particular focus on the human gut microbiome, because these data are amongst the most abundant and cleanest (and therefore most convenient) publicly available, and because establishing the gut microbiome composition is one of the major challenges of the 21st century.

\section{Results}

We designed an analysis to demonstrate that divergent environmental sequences can be investigated fruitfully using networks. Starting with 571,043 sequences from 54 archaeal, 70 bacterial and 7 eukaryotic complete genomes, we first defined 40,584 gene families by clustering sequences with $>=30 \%$ identity over $>=80 \%$ of their lengths as in [32]. We then selected gene families for which finding divergent environmental homologs would be of utmost interest. To do so, we sorted these gene families based on taxonomical and topological criteria in sequence similarity graphs to identify gene families with at least two densely connected modules of sequences, each from a distinct domain of life. In other words, we sought to identify ancient gene families that 
show a strong divergence between the two prokaryotic domains, are rarely transferred between archaea and bacteria, and are widely distributed over each domain. In terms of networks (see Methods), this objective translated into selecting connected components with a conductance of $<0.4$ for each prokaryotic domain. This conservative threshold yielded only 86 gene families $(0.2 \%)$ fulfilling these conditions. These gene families are both broadly distributed across cellular life and show no sign of inter-domain gene transfer, i.e. bacterial sequences formed a group in the graph that was distinct from the group of archaeal sequences. When homologs were present in the 3 domains of life, our graph presented the typical pattern described in [33], with eukaryotic sequences from bacterial origins connecting to bacterial sequences while eukaryotic sequences from archaeal origins connected to archaeal sequences. Bacterial and archaeal homologs within these welldistributed, rarely transferred between domains, gene families showed $>60 \%$ identity on average. This means that our protocol was not restricted to the search for members of highly conserved (in terms of primary sequences) families. All gene families with a strong signal in the network could be exploited. These sequence showed clear homology as well as true divergence between archaeal and bacterial sequences and allowed us to depart from the conventional set of highly conserved markers, such as those found by AMPHORA [34] or PhyEco [35], and hence to offer a complementary analysis of genetic diversity. Given that archaeal and bacterial homologs shared at least $60 \%$ sequence identity, any environmental homologs of these gene families presenting $>40 \%$ divergence (i.e., $<60 \%$ identity) would be more divergent from its homologs than sequences from two distinct domains of life. Such a high divergence, for these families, deserves to be considered significant, possibly hinting at very divergent organismal lineages, and/ or reflecting a major genetic plasticity for these functionally important, apparently ancient gene families. It is noteworthy that the gene families meeting this criterion included genes coding for ribosomal proteins (Table 1).

By contrast to direct BLAST searches [36], we used two rounds of BLAST searches against a local environmental database, comprising 9,865,367 predicted ORFs from about 33 million sequences from 236 metagenomic samples, to search for homologs of the cultured sequences of these conserved families. The first round of BLAST defined a set of environmental homologs with significant hits to known cultured sequences. In the second round, these environmental homologs were used as seeds to look for their own environmental homologs. Using this protocol we retrieved 309,245 sequences. We then applied a stringent criterion to preserve homology relationships between sequences [37], imposing a minimal alignment coverage of $>=80 \%$ between any pair of sequences with $>30 \%$ identity, eventually retaining 131,162 environmental sequences. We thus constructed an environmentally extended version of the network of sequences from cultured organisms, expanding its original gene families through the addition of their environmental homologs. Remarkably, almost all the graphs (82/86) of these extended gene families showed two typical patterns of connection between cultured sequences and their environmental homologs. A first class of environmental sequences was directly connected to the cultured sequences; a second class of environmental sequences was indirectly connected to the cultured sequences, being at a distance 2 (in number of edges) from these known reference genes. Indeed, class 1 environmental homologs (retrieved in the first round of BLAST search) acted as bridges to connect class 2 environmental homologs to the gene family.

All these environmental homologs were then compared against the whole NCBI $n r$ database (July 2013) to look for their closest published relatives (CPR), not only in our networks, but also among all the publicly available sequences from cultured organisms and viruses, defining for each environmental sequence an identity to its CPR (Fig. 1a). $22.5 \%$ of these environmental sequences had $>=95 \%$ identity to their CPRs. However, $44.3 \%$ of the environmental sequences were more divergent, presenting only $60 \%-95 \%$ identity to known sequences. Finally, one third of the environmental homologs (33.2 \%) showed even less similarity to CPRs than this threshold, thus being more distant from their cultured homologs than homolog pairs from different prokaryotic domains were (on average) for these gene families. This first striking result confirms that the genes in cultured organisms are not representative of $77.5 \%$ of the genes of environmental populations. It suggests that genetic and possibly taxonomic diversity are still significantly underestimated at present. The difference between the genetic diversity of these environmental genes and that of cultured microorganisms, for these 82 important markers, raises a general problem. Inferences of microbial genetic resources and microbial taxonomic diversity made from organisms grown in Petri dishes cannot be assumed to hold as general complete descriptions. Our fundamental knowledge about the genetic and possibly the taxonomic composition of microbiomes remains biased by practical considerations. Even gene families with known functions, such as most of our welldistributed ones, have their own share of 'genetic dark matter'. In particular, there is still a substantial number of highly divergent microbial genes in the gut. However, other environments harbor proportionally more of these divergent genes than the gut (Fig. 1a). Indeed, while non gut environmental sequences represent only $17 \%$ of the 
Table 1 Main annotated functions of the gene families for which environmental homologs were identified

\begin{tabular}{|c|c|}
\hline Main annotated functions & Samples with (\#) env. homologs \\
\hline maltose $A B C$ transporter, periplasmic maltose-binding protein & $\mathrm{HMQ}(127) ; J M(6)$ \\
\hline rhomboid family protein & HMQ(907); AA(95); HA(33); JM(29); BB(18); WL(6) \\
\hline phage shock protein A, PspA & $\mathrm{HMQ}(111) ; J M(10) ; B B(3) ; A A(3)$ \\
\hline segregation and condensation protein $B$ & HMQ(1083); HA(120); AA(117); JM(39); BB(30); WL(11) \\
\hline V-type ATP synthase subunit I & $\mathrm{HMQ}(326) ; \mathrm{AA}(16) ; \mathrm{JM}(15)$ \\
\hline protein of unknown function DUF192 & $\mathrm{HMQ}(94) ; \mathrm{AA}(33) ; \mathrm{HA}(23) ; \mathrm{BB}(19) ; \mathrm{WL}(10)$ \\
\hline nucleotide kinase & $\mathrm{HMQ}(9) ; \mathrm{HA}(3)$ \\
\hline $30 \mathrm{~S}$ ribosomal protein S8e & $\operatorname{HMQ}(7) ; \mathrm{AA}(5)$ \\
\hline homoserine kinase & $\mathrm{HMQ}(274) ; \mathrm{AA}(77) ; \mathrm{HA}(43) ; \mathrm{JM}(17) ; \mathrm{BB}(8)$ \\
\hline DNA-directed RNA polymerase subunit $L$ & $\mathrm{HMQ}(4) ; \mathrm{HA}(3)$ \\
\hline 30 ribosomal protein $524 \mathrm{e}$ & $\mathrm{HMQ}(6)$ \\
\hline ribosomal biogenesis GTPase & $\mathrm{HMQ}(980) ; J M(32) ; \mathrm{HA}(23) ; \mathrm{AA}(5) ; \mathrm{WL}(4) ; \mathrm{BB}(3)$ \\
\hline DNA-directed RNA polymerase I, II, and III, 7.3 kDa polypeptide & HMQ(291); AA(34); WL(5); JM(5) \\
\hline protein of unknown function DUF167 & HMQ(94); AA(62); WL(18); JM(3) \\
\hline CoA-substrate-specific enzyme activase & HMQ(919); JM(64); AA(9); WL(4) \\
\hline RNA-binding protein & $\mathrm{HMQ}(717) ; \mathrm{JM}(52) ; \mathrm{WL}(12) ; \mathrm{HA}(10) ; \mathrm{BB}(8) ; \mathrm{AA}(8)$ \\
\hline hypothetical protein & $\mathrm{HA}(43) ; \mathrm{AA}(29) ; \mathrm{BB}(16) \mathrm{HMQ}(9)$ \\
\hline protein of unknown function DUF420 & $\mathrm{AA}(18) ; \mathrm{BB}(8) ; \mathrm{WL}(3)$ \\
\hline twin arginine-targeting protein translocase & HMQ(344); HA(105); AA(105); BB(31); WL(20); JM(17); MB(8); SI(5); G(3) \\
\hline protein of unknown function DUF502 & $\mathrm{HA}(87) ; \mathrm{AA}(59) \mathrm{HMQ}(47) ; \mathrm{BB}(24) ; \mathrm{WL}(15)$ \\
\hline ribonuclease III & HMQ(1370); AA(549); HA(115); JM(66); BB(51); WL(6) \\
\hline polyprenyltransferase & $\mathrm{HMQ}(44) ; \mathrm{AA}(44) ; \mathrm{HA}(32) ; \mathrm{BB}(8) ; \mathrm{WL}(7)$ \\
\hline Rossmann fold nucleotide-binding protein & HMQ(1133); AA(203); HA(79); JM(46); BB(28); WL(18) \\
\hline glutamyl-tRNA reductase & $\operatorname{HMQ}(299) ; \mathrm{HA}(31) ; \mathrm{AA}(31) ; \mathrm{BB}(14) ; \mathrm{WL}(7) ; \mathrm{JM}(7)$ \\
\hline $50 S$ ribosomal protein $L 30 P$ & $\mathrm{AA}(13) \mathrm{HMQ}(12) ; \mathrm{HA}(3)$ \\
\hline $50 S$ ribosomal protein $L 34 \mathrm{e}$ & $\mathrm{HMQ}(1) ; \mathrm{HA}(1) ; \mathrm{AA}(2)$ \\
\hline $50 S$ ribosomal protein $\mathrm{L} 14 \mathrm{e}$ & $\mathrm{AA}(7)$ \\
\hline Pre-mRNA processing ribonucleoprotein, binding region & $\mathrm{HMQ}(6)$ \\
\hline like-Sm ribonucleoprotein, core & $\mathrm{AA}(23) \mathrm{HMQ}(7) ; \mathrm{HA}(4) ; \mathrm{BB}(3)$ \\
\hline 30 s ribosomal protein S26e & $H A(2)$ \\
\hline $30 \mathrm{~S}$ ribosomal protein $\mathrm{S} 3 \mathrm{Ae}$ & $\mathrm{HMQ}(5)$ \\
\hline 30 ribosomal protein S27e & $\mathrm{AA}(8) \mathrm{HMQ}(4)$ \\
\hline cobalamin 5'-phosphate synthase & $\mathrm{HMQ}(871) ; J M(30) ; \mathrm{AA}(17) ; \mathrm{HA}(15) ; \mathrm{WL}(8) ; \mathrm{BB}(3)$ \\
\hline phenylalanyl-tRNA synthetase subunit alpha & HMQ(1698); AA(207); HA(127); JM(66); BB(48); WL(7) \\
\hline cell division protein and ATP-dependent metalloprotease Fts $\mathrm{H}$ & HMQ(1707); HA(338); AA(335); JM(109); BB(79); WL(6) \\
\hline $50 S$ ribosomal protein L1P & HMQ(1231); AA(215); HA(146); JM(65); BB(43); WL(16) \\
\hline AAA family ATPase, Cell Division Cycle CDC48 subfamily protein & $\mathrm{HMQ}(10)$ \\
\hline methionyl-tRNA synthetase & HMQ(1390); AA(211); HA(103); JM(81); BB(35); WL(7); MB(5) \\
\hline $50 S$ ribosomal protein $L 2 P$ & $\mathrm{HMQ}(815) ; \mathrm{AA}(227) ; \mathrm{HA}(147) ; \mathrm{JM}(75) ; \mathrm{BB}(63) ; \mathrm{WL}(3)$ \\
\hline $50 S$ ribosomal protein L22P & HMQ(1765); $\mathrm{AA}(256) ; \mathrm{HA}(150) ; J M(88) ; \mathrm{BB}(53) ; \mathrm{WL}(19) ; \mathrm{MB}(3) ; \mathrm{SI}(3)$ \\
\hline inositol monophosphatase & HMQ(1349); HA(342); AA(307); BB(113); JM(55); WL(15) \\
\hline chaperonin GroEL & HMQ(678); AA(191); HA(128); BB(67); JM(48); WL(5) \\
\hline $50 S$ ribosomal protein $\mathrm{L} 13$ & HMQ(1827); AA(286); HA(142); BB(63); JM(53); WL(8); MB(4); SI(4) \\
\hline $50 S$ ribosomal protein $L 5 P$ & HMQ(2379); AA(520); HA(373); JM(150); BB(116); WL(25); MB(9) \\
\hline
\end{tabular}


Table 1 Main annotated functions of the gene families for which environmental homologs were identified (Continued)

\begin{tabular}{|c|c|}
\hline $30 \mathrm{~S}$ ribosomal protein $\mathrm{S} 12$ & $\mathrm{HMQ}(956) ; \mathrm{AA}(239) ; \mathrm{HA}(155) ; \mathrm{JM}(61) ; \mathrm{BB}(57) ; \mathrm{SI}(20) ; \mathrm{WL}(14) ; \mathrm{MB}(5) ; \mathrm{G}(3)$ \\
\hline $\mathrm{Bcr} / \mathrm{CflA}$ subfamily drug resistance transporter & HMQ(399); JM(19); WL(3) \\
\hline DNA repair and recombination protein RadA & $\mathrm{HMQ}(3327) ; \mathrm{AA}(372) ; \mathrm{HA}(195) ; \mathrm{JM}(109) ; \mathrm{BB}(86) ; \mathrm{WL}(21)$ \\
\hline $50 S$ ribosomal protein $\mathrm{L} 6$ & $\mathrm{HMQ}(1402) ; \mathrm{AA}(239) ; \mathrm{HA}(142) ; \mathrm{JM}(73) ; \mathrm{BB}(55) ; \mathrm{WL}(16)$ \\
\hline methionine aminopeptidase & HMQ(6396); AA(538); HA(316); JM(217); BB(184); WL(22); LM(3) \\
\hline ribonuclease HII & $\mathrm{HMQ}(2476) ; \mathrm{AA}(173) ; \mathrm{HA}(130) ; \mathrm{JM}(60) ; \mathrm{BB}(43) ; \mathrm{WL}(13)$ \\
\hline $50 S$ ribosomal protein $L 23$ & HMQ(2229); AA(253); HA(158); JM(99); BB(46); WL(22); MB(14) \\
\hline molybdenum cofactor biosynthesis protein A & HMQ(2024); AA(146); JM(62); HA(49); BB(40); WL(17) \\
\hline $50 S$ ribosomal protein $L 3 P$ & HMQ(1404); AA(205); HA(103); BB(61); JM(61); WL(8); SI(3) \\
\hline $50 S$ ribosomal protein L18e & $\mathrm{HMQ}(10) ; \mathrm{AA}(5) ; \mathrm{BB}(3) ; \mathrm{HA}(3)$ \\
\hline tryptophanyl-tRNA synthetase & HMQ(1877); AA(213); HA(151); JM(52); BB(45); WL(9) \\
\hline aspartyl-tRNA synthetase & HMQ(3159); AA(348); HA(225); JM(149); BB(95); WL(13) \\
\hline nicotinate nucleotide adenylyltransferase & HMQ(2308); AA(170); HA(138); JM(73); BB(62); WL(15) \\
\hline $30 S$ ribosomal protein S17P & HMQ(1771); AA(264); HA(137); JM(79); BB(50); WL(23); MB(11); SI(10) \\
\hline putative RNA methylase & $\mathrm{HMQ}(1410) ; \mathrm{HA}(35) ; J M(34) ; \mathrm{AA}(20) ; \mathrm{BB}(6) ; \mathrm{WL}(6)$ \\
\hline translation-associated GTPase & HMQ(2629); AA(316); HA(247); JM(97); BB(65); WL(11) \\
\hline $50 S$ ribosomal protein L29 & HMQ(1969); AA(219); JM(82); HA(48); BB(24); SI(22); MB(16); WL(12) \\
\hline appr-1-p processing domain-containing protein & $\mathrm{HMQ}(805) ; J M(55) ; \mathrm{AA}(20) ; \mathrm{WL}(5) ; \mathrm{BB}(3)$ \\
\hline 30 S ribosomal protein $\mathrm{S7}$ & HMQ(1095); AA(313); HA(165); BB(67); JM(67); SI(10); WL(6); G(3) \\
\hline TatD-related deoxyribonuclease & HMQ(3338); $\mathrm{AA}(182) ; \mathrm{HA}(128) ; \mathrm{JM}(86) ; \mathrm{BB}(46) ; \mathrm{WL}(10) ; \mathrm{OM}(5)$ \\
\hline mevalonate kinase & $\mathrm{HMQ}(1131) ; J M(45) ; \mathrm{AA}(16) ; \mathrm{HA}(6)$ \\
\hline O-sialoglycoprotein endopeptidase & $\mathrm{HMQ}(2408) ; \mathrm{AA}(213) ; \mathrm{HA}(163) ; \mathrm{JM}(99) ; \mathrm{BB}(53) ; \mathrm{WL}(5) ; \mathrm{LM}(3)$ \\
\hline MiaB-like tRNA modifying enzyme & $\mathrm{HMQ}(5237) ; \mathrm{AA}(252) ; \mathrm{HA}(197) ; \mathrm{JM}(135) ; \mathrm{BB}(88) ; \mathrm{WL}(12)$ \\
\hline $50 S$ ribosomal protein L15P & HMQ(1798); AA(174); HA(133); JM(103); BB(56); WL(19); MB(4) \\
\hline 6,7-dimethyl-8-ribityllumazine synthase & HMQ(1365); AA(180); HA(149); JM(50); BB(38); WL(25) \\
\hline $30 \mathrm{~S}$ ribosomal protein $\mathrm{S} 5 \mathrm{P}$ & HMQ(3691); AA(416); HA(299); JM(154); BB(105); WL(23); MB(5) \\
\hline carbohydrate kinase, YjeF related protein & HMQ(1547); JM(38); HA(27); AA(13); WL(8); BB(6) \\
\hline ribose-phosphate pyrophosphokinase & HMQ(1807); AA(191); HA(158); JM(70); BB(39); WL(11) \\
\hline replication factor $\mathrm{C}$ small subunit & HMQ(6239); AA(712); HA(225); JM(167); BB(86); WL(19); MB(5) \\
\hline hydrolase & $\mathrm{HMQ}(6012) ; J M(207) ; \mathrm{HA}(45) ; \mathrm{AA}(22) ; \mathrm{BB}(10)$ \\
\hline tyrosyl-tRNA synthetase & HMQ(1123); AA(192); HA(128); JM(65); BB(55); WL(6) \\
\hline $50 S$ ribosomal protein L18P & $\mathrm{HMQ}(14)$ \\
\hline Fmu (Sun) domain-containing protein & $\mathrm{HMQ}(2680) ; \mathrm{JM}(76) ; \mathrm{AA}(50) ; \mathrm{HA}(47) ; \mathrm{BB}(20) ; \mathrm{WL}(12)$ \\
\hline 30 S ribosomal protein $\mathbf{S 2}$ & HMQ(834); AA(225); HA(130); JM(48); BB(44); WL(8) \\
\hline leucyl-(isoleucyl-) and (valyl-)tRNA synthetase & $\mathrm{HMQ(2653);} \mathrm{AA(112);} \mathrm{JM(78);} \mathrm{HA(75);} \mathrm{BB(51);} \mathrm{WL(7)}$ \\
\hline
\end{tabular}

Environments of origins were HMQ: Human microbiome Qin2010; JM: Japanese Microbiome; AA: Antarctica Aquatic; HA: Hot Aloha; BB: Botany Bay; WL: Washington Lake; MB: Monterey Bay; SI: Sapelo Island; G: Glacier; LM: Lean Mice; OM: Obese Mice.

retrieved homologs, they account for significantly larger proportions amongst the most divergent sequences, showing less than $50 \%$ identity to CPRs (prop test pvalue of $2 \mathrm{e}-16)$. The median of the distribution of the distance to a CPR lies around $40 \%$ for homologs from other environments than the gut while it lies around $72 \%$ for homologs from gut samples. This difference is likely due to the Human Microbiome Project, which has produced relatively many highly divergent sequences from gut samples. Strong sequencing efforts focusing on non-gut environments would help identify more hard-tofind, highly divergent environmental homologs. This contrasted observation a posteriori justifies the choice of gut samples as a major part of our dataset, and makes it obvious that massive metagenomic analyses are a relevant way to reveal more as yet unknown genetic diversity.

Importantly, the network topology provides additional insight concerning microbial genetic diversity. The 


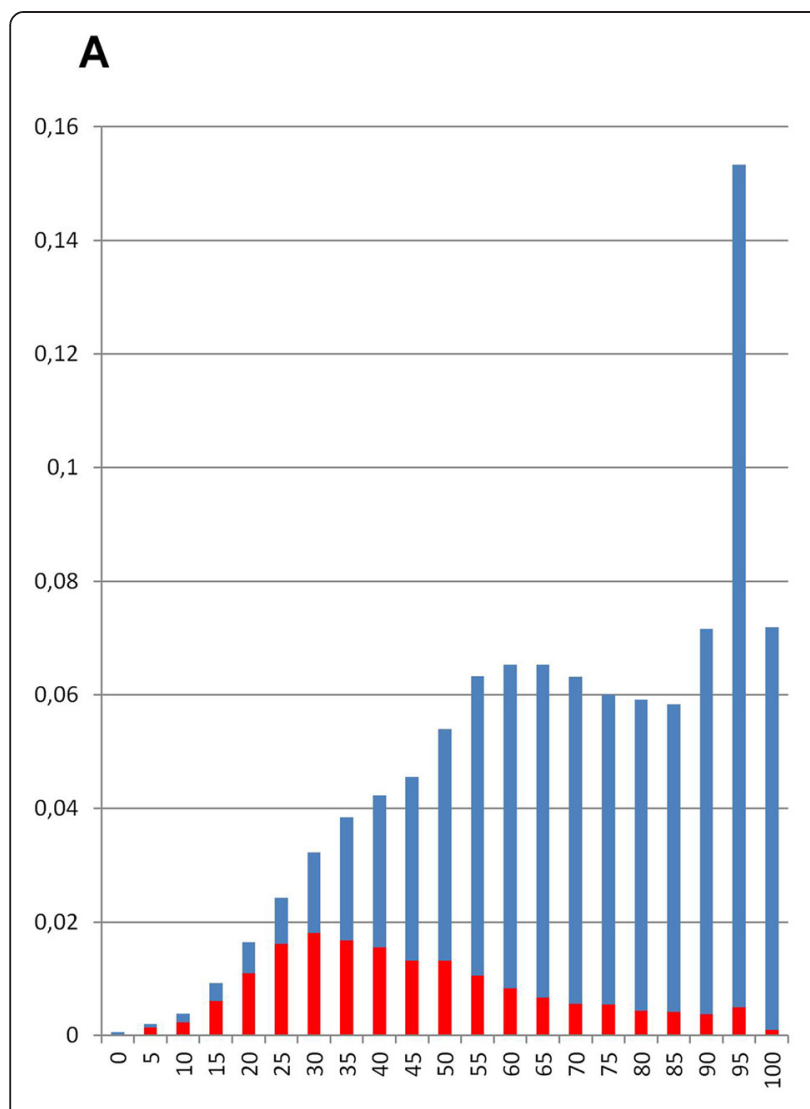

B
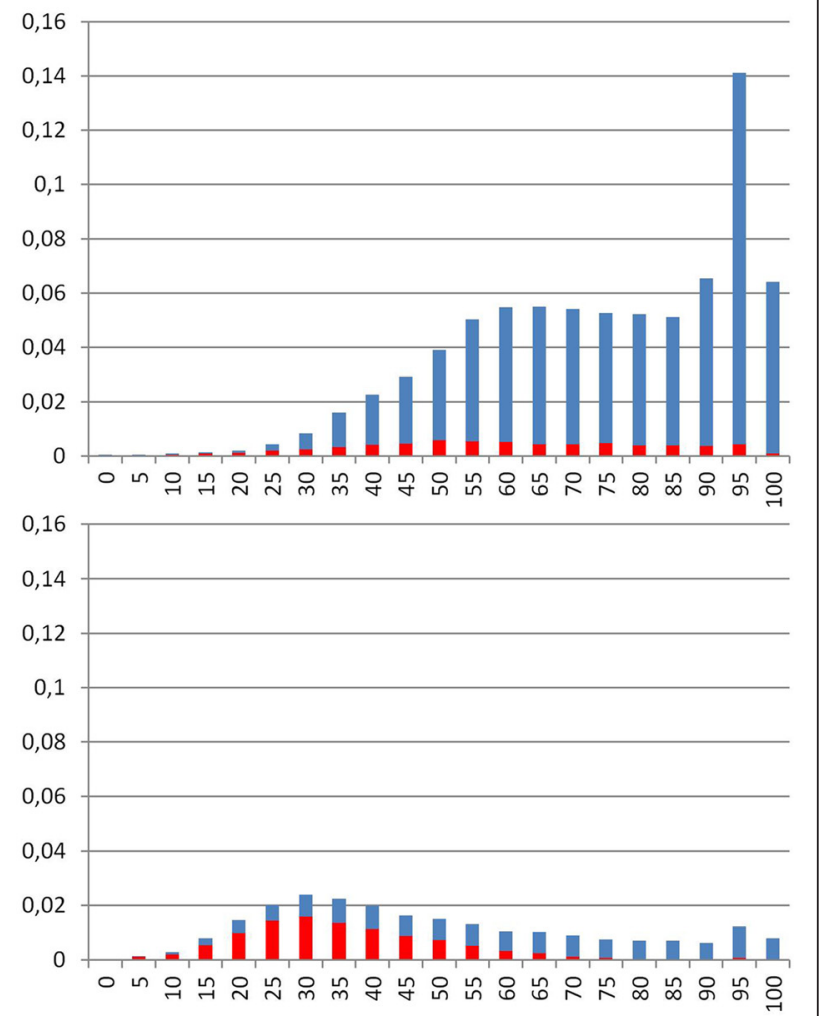

Fig. 1 Distribution of identity percentage to closest published relative for environmental sequences. For each of the 131,162 environmental sequence retrieved by our protocol, the closest published relative is identified as the best BLAST hit against July 2013 release of $n r$ NCBI database. Identity percentage between the two sequences, shown in abscissa, is computed as the hit coverage relatively to the smallest sequence multiplied by the BLAST identity percentage. The proportion of environmental sequences showing a given identity percentage is given in ordinate, in blue for sequences from human gut microbiome and in red for others. a) Class1 (direct link to cultivated hosts sequences) and class2 (indirect link) are cumulated. b) Class 1 and Class2 are separated on top and bottom, respectively

distribution of identity to a CPR for class 2 environmental homologs, i.e. the sequences indirectly connected to cultured prokaryotes sequences, is significantly lower, compared to that of class 1 homologs, i.e. the sequences directly connected to cultured prokaryotic sequences (one-sided KS test, p-value 1e-3) (Fig. 1b). Consequently, sequences far away, i.e. separated by more than one edge, from cultured samples in this network are also generally more divergent. Contrary to traditional surveys of genetic diversity based on BLAST searches that only take into account direct matches, the network topology allows the detection of more distant relationships between homologs, through indirect paths of increasing length that nonetheless represent homology.

One might worry that iterative rounds of BLAST, using the last retrieved sequences as seeds, would eventually retrieve sequences unrelated to initial seeds, despite the additional criterion of $80 \%$ mutual cover between two sequences to be considered homologs. This should not be the case if gene families under investigation occupy relatively isolated regions of the genetic space, because each new BLAST round should yield more of the genetic diversity of such gene families until exhaustion is reached. Accordingly, we observed a much lower number of class 2 than class 1 sequences. Figure $1 \mathrm{~b}$ also shows that sequences from gut samples are found both amongst class 1 and class 2 environmental homologs, but in significantly greater proportions amongst class 1 homologs (proptest p-value of $2 \mathrm{e}-16$ ). By contrast, sequences from other environmental samples are especially numerous in class 2 homologs. In particular, in this dataset, marine (Botany Bay), cold (Antarctica Aquatic) and hot (Hot Aloa) water environments proved very rich in these most divergent environmental homologs. This difference in relative network positions demonstrates the impact of the strong sequencing effort targeting the human gut microbiome that revealed some (but by no means all) microbial diversity in the environment.

Moreover, the structure of our graphs (Figs. 2 and 3) also allowed us to distinguish groups of divergent 


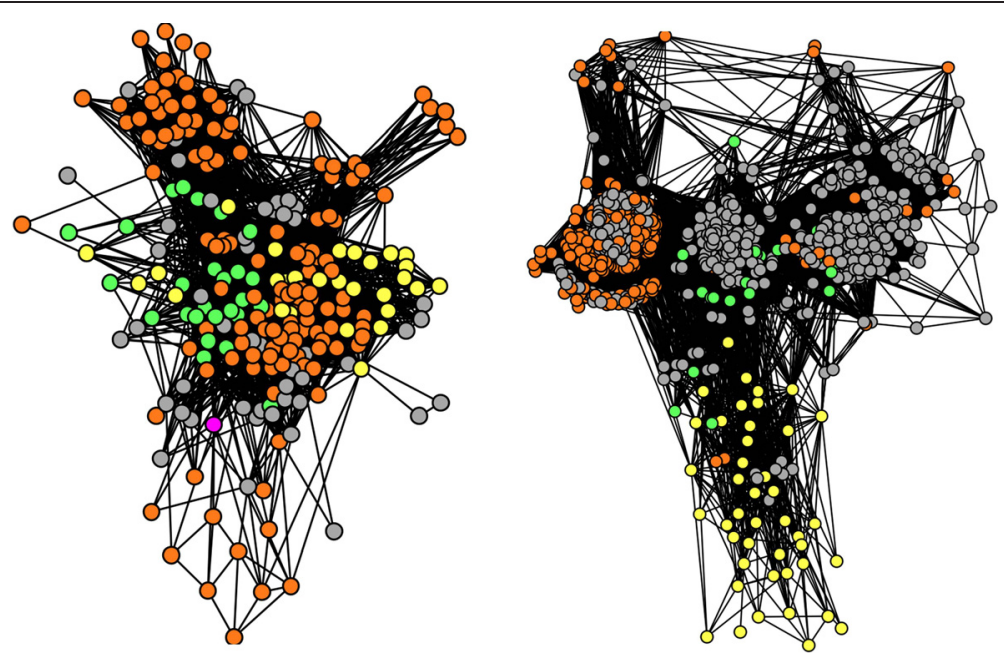

Fig. 2 Sequence similarity networks for cultivated hosts sequences and their associated environmental sequences. Each node corresponds to a sequence. Two nodes are connected when they share $>=30 \%$ identity, for a hit covering $>=80 \%$ of both of their lengths, with a BLAST score $<1$ e-5. Sequences are yellow for Archaea, green for Bacteria, orange for environmental homologs whose identity to their closest published relative is lower than $60 \%$, and grey for environmental homologs whose identity to their closest published relative is higher than $60 \%$. Left: DUF167 protein, right: cobalamine phosphate synthase

environmental homologs, whose identity to CPRs was lower than $60 \%$, defining 562 tight clusters (network cliques with exclusively highly divergent environmental content) in the graphs of 69 gene families under study, including ribosomal proteins. Since identical (redundant) sequences had been preliminarily filtered out, the existence of these groups of divergent environmental homologs means that, occasionally, many related variants of a given group of divergent environmental homologs are present in nature. Importantly, these cliques should not be confused with phylotypes [38], because there was a wide range of genetic variation between environmental sequences within these groups, as measured by average nucleotide or amino acid identity (Fig. 4a and Additional file 1: Figure S1). While a few of these groups had an average identity close to 1 , indicating very similar sequences, most cliques had a much lower average residue identity, confirming that the sequences therein were not just close variants of a single sequence produced by sequencing errors. In fact, the genetic variation within these groups of environmental sequences was comparable, if only slightly smaller, to that of either archaeal or

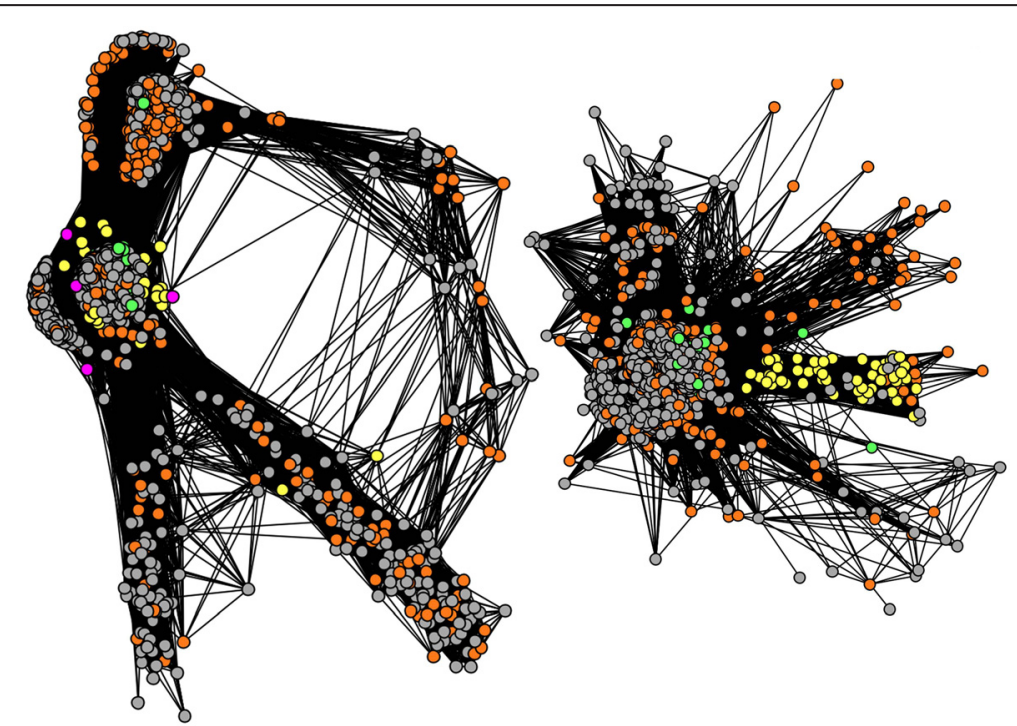

Fig. 3 Other sequence similarity networks for cultivated hosts sequences and their associated environmental sequences. The color code is the same as in Fig 2. Left: metalloendoprotease, right: ribosomal protein RPL23/25 


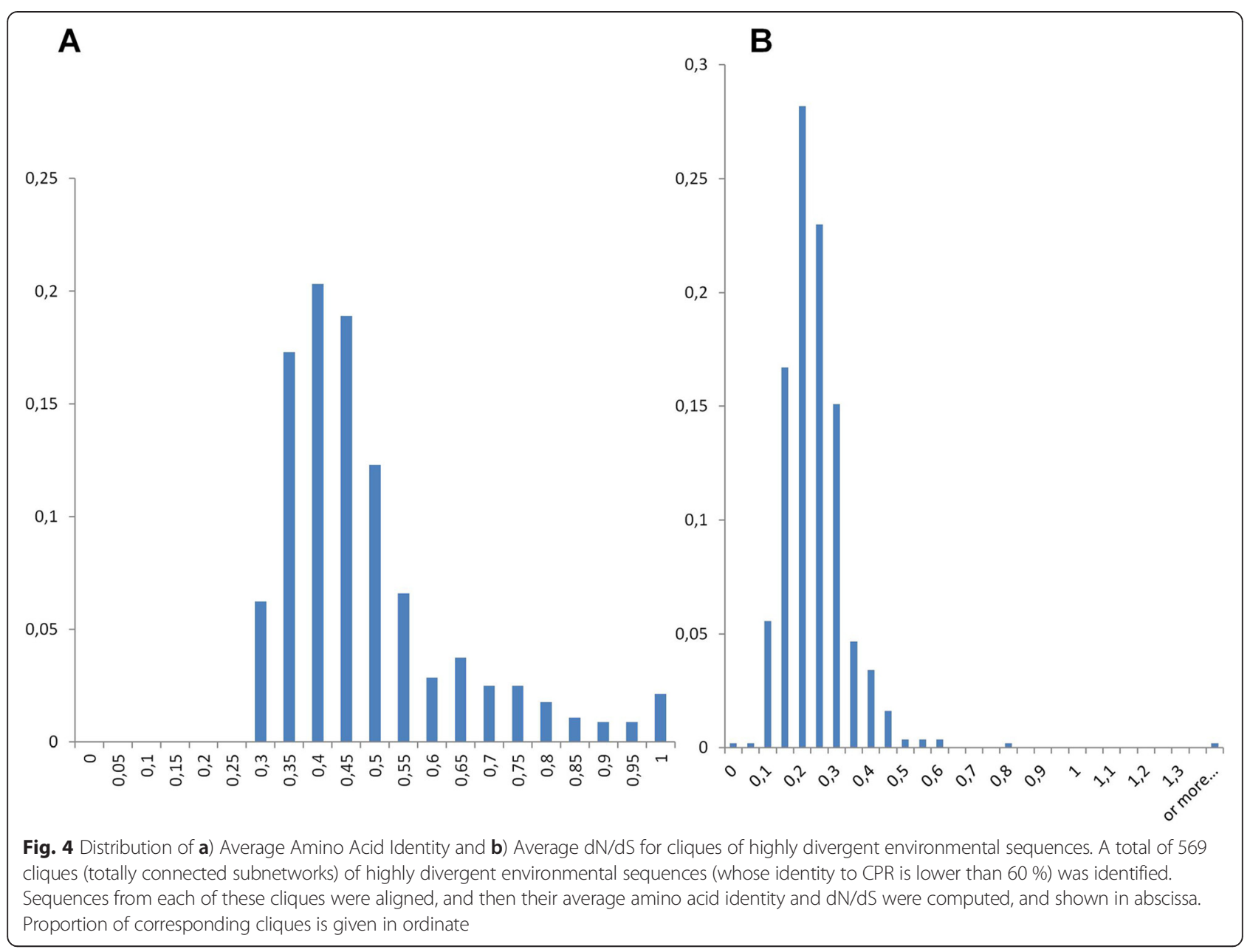

bacterial cliques of the networks, a remarkable property compatible with the hypothesis that these environmental homologs belong to highly diversified taxonomical groups. Moreover, careful analyses with RDP [39] of the alignments of these related variants showed no evidence of either recombination or chimerism in these divergent environmental homologs. Furthermore, dN/dS estimates for these environmental divergent homologs revealed that most of these gene forms were under purifying selection (median of the average $\mathrm{dN} / \mathrm{dS}$ distribution 0.22 , Fig. $4 \mathrm{~b}$ ). These last two observations confirmed that there were very few if no confounders like PCR errors, chimeras and pseudogenes involved in this genetic diversity.

Consequently, our most comprehensive graph-based representation of genetic diversity in metagenomic samples reveals an impressive number of gene families with potentially coding, highly divergent, environmental homologs. Once again, it is worth stressing that most of this genetic diversity cannot be represented nor can it be simultaneously analyzed with their homologs from cultured organisms in conventional phylogenetic analyses, because the vast majority of our cliques of distant homologs cannot be confidently aligned with their cultured homologs. Indeed, only 289 out of 562 environmental cliques produced alignments with more than 10 unambiguously aligned positions, as assessed by GBlocks [40]. Thus, sequence similarity networks not only provide a novel, sufficient, but also a broader type of evidence for identifying clusters of highly divergent environmental sequences with respect to sequences from cultured organisms. The exploration of microbial dark matter therefore directly benefits from this alternative representation of the relationships in molecular data, and the analysis of these paths and cliques.

As a further indication that sequence similarity networks nonetheless also provide evidence for diversity studies consistent with that of phylogenetic trees and networks, we estimated phylogenetic trees including the minority of groups of environmental sequences that could be aligned with sequences from cultured organisms from at least 2 domains of life. These expectedly short alignments were used to reconstruct 289 maximum likelihood unrooted trees for 65 gene families. Some of these divergent environmental homologs 
branch within the archaeal and bacterial clans for some genes, and some also branch outside the archaeal and bacterial clans [41] (Fig. 5). Such a phylogenetic position is compatible with major deep branching divisions. Overall, this analysis further confirms the large phylogenetic depth within groups of environmental homologs detected in the network, and their significant phylogenetic distance to sequences present in cultured lineages in our dataset. Interestingly, we observed such divergent lineages of environmental genes in human microbial gut samples.

\section{Discussion}

Our inclusive multi-marker network-based approach efficiently recovered novel evidence of highly divergent microbial genes, possibly partly originating from microbial dark matter, even in the human gut. Of course, one must be careful when interpreting this result, because the divergence between genes does not necessarily reflect the same phylogenetic divergence between organisms that carry those genes. However, although we have not been looking at $16 \mathrm{~S}$ data, when one considers the gene families for which we report massively divergent environmental homologs under purifying selection, it must be noted that many (18) of the studied gene families with these highly divergent forms are ribosomal proteins (also commonly used in phylogenetic reconstruction [42]) and that the broad distribution and infrequent inter-domain transfer of these gene families suggests they all perform critical functions in cells. Moreover, the detection of groups of divergent environmental homologs from these families provides evidence that these divergent gene forms are not independent genome specific variants (i.e. occasional variants coming from individual, unrelated genomes) but are shared by different related genomes. That related genomes have largely diversified copies for these important gene families suggests that a significant fraction of the environmental divergent genes may come from gene families with otherwise known functions in cultured organisms. If one assumes that these variants come from known lineages, then our results suggest that functional annotation in metagenomic studies is incredibly challenging, because adaptation to different environments must lead to massive molecular changes even for such gene families. In that case, environmental divergent genes would partly result from an impressive plasticity of these genes families, affecting even ribosomal proteins, consistently with [9]. Otherwise, these genes could be the extensively diverged descendants of ancient gene duplications (with a potential history of mosaicism or gene fusion). Therefore, when our finding is cautiously interpreted at the gene level, it indicates that even gene families that are well-distributed among widely divergent lineages have undergone substantial sequence evolution in the environment.

However, the gene level is not the only possible level of explanation for the massive diversity observed in the environment. The detection of groups of environmental homologs (for which we cannot determine whether they are orthologs or paralogs, since precisely we lack their genomes of origins), more divergent on average from any known cultured or viral sequence than the observed divergence between archaea and bacteria for these gene families can also be interpreted at a higher level of

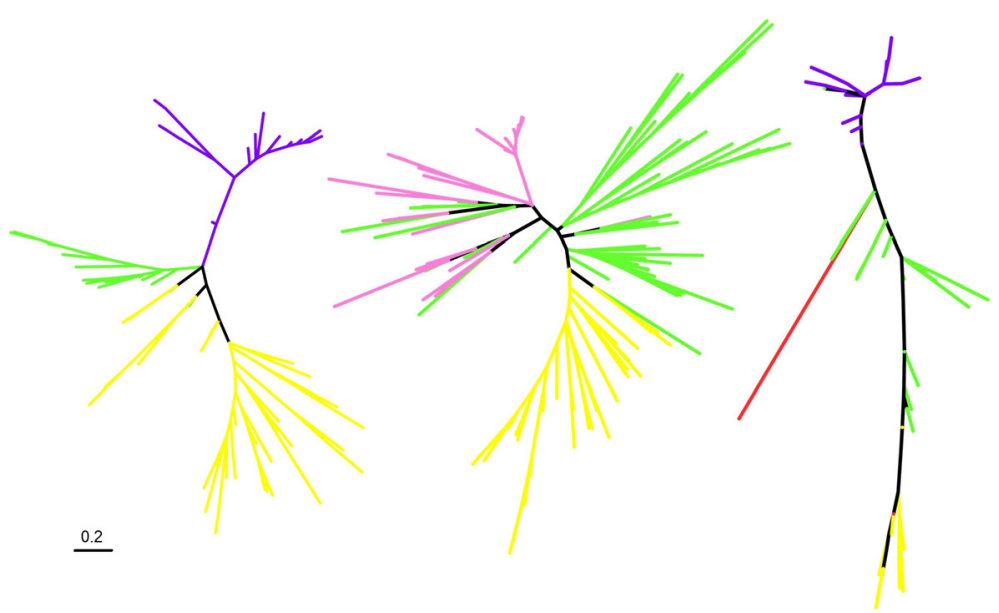

Fig. 5 A phylogeny-based illustration of the actual divergence of some of the environmental homologs detected in our networks. Maximum likelihood phylogenetic trees were based on sequences of archaeal (yellow), bacterial (green), eukaryotes (red) and a subset of the alignable positions of some environmental homologs (purple for gut sequences, pink for other environments), extracted using a maximal clique search. Three trees presenting a remarkable pattern are shown here. Left: cobalamine phosphate synthase (27 alignable positions), middle: RPL29 (52 alignable positions), right: metalloendoprotease (10 alignable positions). A scale bar for branch lengths (number of substitutions per site) is given on bottom left 
biological organization. In other words, another (non-exclusive) explanation for this genetic variation might also be to consider that some novel lineages of microbes remain to be discovered. Then, the nature of the hosts of such highly divergent homologs in otherwise "cell-ubiquitous" gene families becomes a particularly intriguing question. Do divergent lineages of environmental genes point to divergent, deep-branching lineages of organismal hosts? There are good reasons to assume the present analysis, as many studies before [9], has revealed molecular cues of novel major life divisions in the environment. Of note, this seems to be the case also in the human gut. First, according to the literature, almost all the genes from these gut samples come from microbial organisms [30]. Second, since most of these genes are under purifying selection, and since they belong to relatively ubiquitous, ancient families, including ribosomal proteins, they are probably adaptive to some hosts. Thus, if taken at face value, these deep branching lineages and groups of divergent environmental genes suggest that some major organismal divisions have still not been described and are present in the human gut.

Even though environmental divergent sequences showed no match to known viral sequences, the possibility that some of these environmental divergent forms are carried by viruses rather than hosted in cells remains of course open. But invoking a viral host would either mean that viruses play the role of vehicles, mobilizing these divergent genes from unknown microbial organisms (hence signing the presence of novel organismal divisions), or that there exists a bona fide evolutionary connection between sequences from unknown viruses and genes from 82 ancient gene families well-distributed amongst multiple divergent cellular organisms. This connection would then implicate an ancient relationship between cell and viral lineages in the origin of these genes, as debated in [4, 43], and thus suggest a shared ancestry between large viruses and cells [44]. In either case, the host lineage of the divergent environmental genes would be distantly related to known organismal lineages in a way that may challenge our knowledge of evolutionary microbiology.

\section{Conclusions}

Overall our protocol identifies much more divergent (environmental) gene forms than previous analyses of metagenomic data. Our approach complements and expands the scope of diversity analyses based on direct BLAST searches, trees of ribosomal genes, relatively stringent networks of ribosomal genes, or $16 \mathrm{~S}$ phylotypes, and should prompt further sequencing of complete environmental genomes by providing primers to probe diversity for cells with highly unusual genes. More precisely, existing libraries could be probed for the hosts of these genes, using primers designed from the alignments of the highly divergent environmental genes detected in our graphs, in order to isolate and amplify their genomic material. Future analyses may also further target these hosts by cell sorting and in situ hybridization analyses on gut microbiome samples to provide microbiological evidence regarding the extent of the microbial dark matter within the environment and within our own body. Of course, the detection of orthologs in larger datasets using networks (currently something we have not achieved) could in principles also greatly help to this endeavour. The potential discovery of novel groups would be of major importance in microbiology and evolutionary biology. Just as the discovery of Archaea spawned an entire research field [45], one can imagine that significant progresses may also result from the discovery of major lineages and remarkable variants of important gene families within the microbial dark matter. As a follow up of this proof of concept analysis, we encourage larger comparative studies, with expanded datasets, including more sequences from cultured organisms and from more environments.

\section{Methods}

\section{Constitution of the datasets}

The initial dataset comprised 564,448 protein sequences from 116 prokaryotic genomes (54 Archaea and 70 Bacteria, sampled in order to cover prokaryotic diversity as in [33]), 7 eukaryotic genomes (Oryza sativa, Paramecium tetraurelia, Saccharomyces cerevisiae, Entamoeba histolytica and the nucleomorphs of Guillardia theta, Bigelowiella natans and Hemiselmis andersenii) and various MGE (plasmids and viruses). In addition to this, we used MetaGeneAnnotator [46] to predict 9,456,237 protein sequences longer than 50 amino acids, from $31,779,190$ contigs/reads, issued from 236 samples of microbial metagenomics (excluding projects of viral and plasmid metagenomics, see Additional file 1: Table S1 for a detailed list).

\section{Selection of gene families with a strong ancient genealogical signal}

We reconstructed the gene network of the initial dataset, defining significant similarity for sequences with a BLAST e-value $<1$ e- 5 and $>30 \%$ identity, inferred as the BLAST identity multiplied by hit coverage for the shortest sequence, as in [47]. We computed the conductance [48] of each Domain in each connected component of this network, estimated by the ratio of external edges (from nodes within the Domain to nodes outside the Domain) over internal edges (between nodes within the Domain only). We found 86 connected components with a conductance lower than 0.4 for two Domains, i.e. in which sequences were clearly structured in at least 2 
conserved groups corresponding to 2 Domains of Life between which there was no or little evidence of LGT in the graph. These 86 components, called nuclei hereafter, comprised 10,673 sequences. They correspond to homologous sequences, but not necessarily to orthologs.

\section{Rounds of BLAST searches to gather environmental homologs}

We BLASTed the 10,673 nuclei sequences against the 9,456,237 predicted environmental ORFs (TBLASTN, e-value threshold $=1 \mathrm{e}-5,500 \mathrm{hits})$. Then, the 232,660 retrieved environmental ORFs were used as seeds for a second round of BLASTN (to avoid possible detection problems caused by frameshifts, e-value threshold $=1 \mathrm{e}-5$, 500 hits) against the predicted environmental ORFs to look for their own homologs in the environment. This protocol yielded a dataset with a total of 309,245 sequences (298,578 environmental ones) to reconstruct a sequence network with nuclei and environmental sequences.

\section{Reconstruction of exploratory similarity networks}

Environmental sequences were translated into proteins, and the previous 309,245 sequences were BLASTed all against all (BLASTP, e-value threshold $=1 \mathrm{e}-5,5000$ hits to avoid artefactual increases in the distance between environmental ORFs and nuclei in similarity networks, in case a given sequence from a nuclei hits $>500$ environmental ORFs). BLAST results were used to reconstruct an exploratory similarity network, where nodes represent sequences and a "homology edge" is created between two nodes if the two sequences show a BLAST e-value $<1 \mathrm{e}-5$, more than $30 \%$ identity and a match covering at least $80 \%$ of both the compared sequences. This latter condition ensures that no two sequences are connected by the mere sharing of a gene fragment (e.g. a domain). This similarity network retained 131,162 environmental sequences, and yielded 82 connected components: adding environmental sequences made most of the nuclei grow into independant connected component, but a in a few cases two nuclei were united into the same component.

\section{Analyses of the exploratory similarity networks}

All the environmental sequences from each of the 82 connected components were BLASTed against the July 2013 release of Genbank $n r$ database (BLASTP, e-value threshold 1e-5) to quantify the identity percentage between each of these environmental ORFs and its closest sequence in $n r$, called closest published relative (CPR). Thus, comparison was made against all eukaryotic and prokaryotic sequences deposited at this date. CPR were computed relatively to the shortest sequence, as BLAST identity multiplied by hit coverage for the shortest sequence. Moreover, the topological distance of each of these environmental ORFs to a reference genome from the three Domains of life was estimated by the number of edges separating them in the graph. Class1 sequences were identified as environmental ORFs directly connected to a nucleus sequence. Class2 sequences were identified as environmental ORFs directly connected to a class1 sequence, but not to a nucleus sequence.

\section{Visualization of sequence spaces and landscapes}

All similarity networks were displayed with Gephi v0.8.1 software (https://gephi.org), using the 'Yifan-Hu multilevel' layout. This particular layout ensures a maximal readability of the connected components, by placing node from densely connected parts of the network close together.

Extraction and analysis of highly divergent closely related environmental sequences

Maximal cliques (totally connected subnetworks) of environmental sequences whose identity to a CPR was lower than $60 \%$ were identified in the previous 82 components using MACE [49], yielding 562 subsets of closely related environmental sequences. Each of these subsets was aligned with MUSCLE v3.8 [50], then tested for potential recombination with RDP3 [39]. Corresponding nucleotide alignments were also analyzed with yn00 software from the PAML v4.7 package [51, 52]. For each clique, average $\mathrm{dN} / \mathrm{dS}$ ratio was computed as the average of pairwise omega parameters. MUSCLE alignments were used to compute average residue identity, as the mean of pairwise identity percentages for each clique. All scripts used to measure conductances and network distances, and to extract largest maximal cliques in our networks are available from PL upon request.

\section{Phylogenetic analyses of closely related environmental sequences}

For phylogenetic purposes, environmental clique amino acid sequences were aligned with their nucleus counterparts using MUSCLE, and ambiguously aligned regions were discarded with GBlocks v0.91b [40]. Only 289 streamlined alignments retained more than 10 residues, confirming that a large number of cliques contained extremely distant homologs of nucleus sequences. Unrooted maximum likelihood trees were then reconstructed from these 289 alignments using PhyML v3.0 [53] with default parameters.

\section{Reviewers' comments}

Reviewer's report 1 (Eugene Koonin, National Center for Biotechnology Information, USA)

Summary : Lopez and colleagues report an extensive analysis of metagenomic sequences that demonstrates 
the presence of highly diverged versions of (nearly) universal genes including 18 coding for ribosomal proteins. The results are deemed compatible with the existence of "new divisions of life". I think this cautious conclusion is justified. Although some of the sequences are more distant from bacteria and archaea than the latter are from each other, a conservative standpoint is that these sequences are more likely to represent fast evolving bacteria or archaea than new domains of cellular life. Again, the authors are quite cautious in their interpretations and never overstate their case. All in all, this is an interesting and important article.

Author's response: we thank the reviewer for his appreciation of our work.

Recommandations: I have no major recommendations. Minor recommendation: it seems desirable to cite and briefly discuss the following recent publications that are directly relevant to the theme of this article: Luef $B$, Frischkorn KR, Wrighton KC, Holman HY, Birarda G, Thomas BC, Singh A, Williams KH, Siegerist CE, Tringe SG, Downing KH, Comolli LR, Banfield JF. Diverse uncultivated ultra-small bacterial cells in groundwater. Nat Commun. 2015 Feb 27;6:6372 Brown CT, Hug LA, Thomas BC, Sharon I, Castelle CJ, Singh A, Wilkins MJ, Wrighton KC, Williams KH, Banfield JF. Unusual biology across a group comprising more than $15 \%$ of domain Bacteria. Nature. 2015 Jul 9;523(7559):208-11

Author's response: we agree with the reviewer and have now cited and discussed these two important articles in the introduction and conclusion.

Minor Issues : The text of the article requires some additional editing, preferably, by a native English speaker.

Author's response: the manuscript has been edited by a native English speaker.

Reviewer's report 2 (William Martin, HeinrichHeine-Universität, Germany)

Summary : The authors present novel (network) methods to address diversity in envirnomental sequences. The paper is very interesting and technically an important step in the right direction to explore more of what we do not know about environmental microbial diversity. It can be published as is in my view, some language editing by a native speaker would help, I listed some but by no means all style and usage problems below.

Author's response: we thank the reviewer for his comments and for pointing out the interest of the method.

\section{Recommandations:}

p. 1.

1. 30 life levels? reword, not clear

143 , tres of life $->$ phylogenetic trees papers should be line numbered continuously in the future, please, makes commenting easier.

life division $->$ divisions of life

have been constant progresses - has been constant progress

obsidian Pool , capitalization

polymorphism. $30 \%$ of the genes $->$ polymorphism. Thirty percent of the genes (never start a sentence with a numeral)

Likewise, in 2005, Chouari et al. : reference number?

In 2012, Narasingarao et al. : reference number?

it seems that one could in principle come up with some novel microbial lineages, at various levels of the biological classification $->$ novel microbial lineages are being discovered through environmental sequencing.

microbial dark universe : was dark matter already introduced?

these data are amongst the most numerous $->$ these data are amongst the most abundant

seeked to identify — sought to identify

families fulfilled these - families fulfilling these

protocole-protocol

important amount of microbial divergent genes substantial number of divergent microbial genes

proved its efficiency to unravel - was efficient in uncovering

such gene families ! - why !

In either case, the host lineage of the divergent environmental genes would be

439 distantly related to known organismal lineages in a way that may challenge our

knowledge in evolutionary 440 microbiology. As a follow up of this proof of concept

441 analysis, it would next be interesting to perform larger comparative studies, with

442 expanded datasets, including more sequences from cultured organisms and from more

443 environments, this new dataset might identify other ancient, divergent, rarely

444 transferred between domains gene families.

Sorry, is that essential and what is it supposed to mean?

theories on the origins of eukaryotes [41] - Woese did not revolutionize theories for eukaryote origin, he (co-)discovered archae(bacteri)a and introduced the concept of microbial phylogeny.

Author's response: typos have been corrected and the manuscript has been edited in accordance with the reviewer's points.

Reviewer's report 3 (James McInerney, University of Manchester, U.K.)

Summary : This is an interesting paper that demonstrates quite clearly that environmental sequence space is not well known and that future work should aim to 
explore this. I have no real problems with the manuscript, just some minor comments.

Author's response: We thank the reviewer for his interest in our work.

\section{Recommandations:}

Major Comments: None. Minot comments On Fig. 5, can you put a scale bar on the figures?

Author's response: A scale bar has been added to the figure.

Minor Issues: Minor points: 1 . The language needs a little work, with some of the sentences having awkward phrasing. 2. The paper is quite long. The introduction and the discussion in particular were quite long and might benefit from being reduced in length. 3 . When phylogenies were made from those sequences that could be aligned, how likely is it that long-branch attraction occurred and therefore pulled the sequences out of the bacterial or archaebacterial groups?

Author's response: 1) A native English speaker has edited the manuscript. 2) Introduction and discussion have been shortened so that the article is easier to read. 3) Long-branch attraction could indeed be responsible for the particular location of environmental sequences in the trees from Fig. 5. However, sequences have been trimmed by Gblocks prior to reconstruction, yielding a very small number of positions that could be reliably aligned, which should reduce (but not rule out) the likelihood of long-branch attraction. We take this opportunity to recommend again the use of networks instead of trees for exploring high sequence divergence.

\section{Additional files}

Additional file 1: Table S1. Environmental dataset. A total of 236 environmental microbial samples was used in this study. For each sample, environmental origin, number of predicted Open Reading Frames (total and longer than 50 amino acids) and data source are given. Figure S1 Distribution of Average Nucleotide Identity of highly divergent environmental sequences. A total of 569 cliques (totally connected subnetworks) of highly divergent environmental sequences (whose identity to CPR is lower than $60 \%$ ) was identified. Sequences from each of these cliques were aligned, then their average nucleotide identity were computed, and shown in abscissa. Proportion of corresponding cliques is given in ordinate. (PDF $89 \mathrm{~kb}$ )

\section{Competing interests}

We declare no competing interests.

\section{Authors' contributions}

$P L$ and $E B$ designed the study, performed the analysis, and wrote the manuscript. SH reconstructed the networks. All authors read and approved the final manuscript.

\section{Acknowledgements}

This work was supported by the European Research Council FP7 [2007-2013 Grant Agreement n $\left.{ }^{\circ} 615274\right]$ to E.B, and S.H. was supported by a Genome Canada/Genome Quebec research grant (Genorem) awarded to M. St-Arnaud and M. Hijri. We thank R.M. Burian, D. Bhattacharya and J.W. Leigh for critical reading

\section{Author details}

'Team 'Adaptation, Integration, Reticulation, Evolution' - UMR CNRS 7138 Evolution Paris Seine - Institut de Biologie Paris Seine - Université Pierre et Marie Curie, 7 quai St Bernard, 75005 Paris, France. ${ }^{2}$ Département de Sciences Biologiques, Institut de recherche en biologie végétale, Université de Montréal, Montréal, QC H1X 2B2, Canada.

Received: 30 July 2015 Accepted: 13 October 2015

Published online: 26 October 2015

\section{References}

1. Hugenholtz P, Pitulle C, Hershberger KL, Pace NR. Novel division level bacterial diversity in a Yellowstone hot spring. J Bacteriol. 1998;180(2):366-76.

2. Chouari R, Le Paslier D, Dauga C, Daegelen P, Weissenbach J, Sghir A. Novel major bacterial candidate division within a municipal anaerobic sludge digester. Appl Environ Microbiol. 2005;71(4):2145-53. doi:10.1128/ AEM.71.4.2145-2153.2005.

3. Rappe MS, Giovannoni SJ. The uncultured microbial majority. Annu Rev Microbiol. 2003:57:369-94. doi:10.1146/annurev.micro.57.030502.090759.

4. Boyer M, Madoui MA, Gimenez G, La Scola B, Raoult D. Phylogenetic and phyletic studies of informational genes in genomes highlight existence of a 4 domain of life including giant viruses. PLoS One. 2010;5(12), e15530. doi:10.1371/journal.pone.0015530.

5. Dinsdale EA, Edwards RA, Hall D, Angly F, Breitbart M, Brulc JM, et al. Functional metagenomic profiling of nine biomes. Nature. 2008;452(7187):629-32. doi:10.1038/nature06810.

6. Luef B, Frischkorn KR, Wrighton KC, Holman HY, Birarda G, Thomas BC, et al. Diverse uncultivated ultra-small bacterial cells in groundwater. Nat Commun. 2015;6:6372. doi:10.1038/ncomms7372.

7. Marcy Y, Ouverney C, Bik EM, Losekann T, Ivanova N, Martin HG, et al. Dissecting biological "dark matter" with single-cell genetic analysis of rare and uncultivated TM7 microbes from the human mouth. Proc Natl Acad Sci U S A. 2007;104(29):11889-94. doi:10.1073/pnas.0704662104.

8. Lagier JC, Armougom F, Million M, Hugon P, Pagnier I, Robert C, et al. Microbial culturomics: paradigm shift in the human gut microbiome study. Clin Microbiol Infect. 2012;18(12):1185-93. doi:10.1111/1469-0691.12023.

9. Brown CT, Hug LA, Thomas BC, Sharon I, Castelle CJ, Singh A, et al. Unusual biology across a group comprising more than $15 \%$ of domain Bacteria. Nature. 2015;523(7559):208-11. doi:10.1038/nature14486.

10. Beja O, Suzuki MT, Heidelberg JF, Nelson WC, Preston CM, Hamada T, et al. Unsuspected diversity among marine aerobic anoxygenic phototrophs. Nature. 2002:415(6872):630-3. doi:10.1038/415630a.

11. Giovannoni SJ, Britschgi TB, Moyer CL, Field KG. Genetic diversity in Sargasso Sea bacterioplankton. Nature. 1990;345(6270):60-3. doi:10.1038/345060a0.

12. Moreira D, Rodriguez-Valera F, Lopez-Garcia P. Metagenomic analysis of mesopelagic Antarctic plankton reveals a novel deltaproteobacterial group. Microbiology. 2006;152(Pt 2):505-17. doi: 10.1099/mic.0.28254-0.

13. Murray AE, Grzymski JJ. Diversity and genomics of Antarctic marine microorganisms. Philos Trans R Soc Lond B Biol Sci. 2007;362(1488):2259-71. doi:10.1098/rstb.2006.1944.

14. Chouari R, Le Paslier D, Daegelen P, Ginestet P, Weissenbach J, Sghir A. Molecular evidence for novel planctomycete diversity in a municipal wastewater treatment plant. Appl Environ Microbiol. 2003;69(12):7354-63.

15. Derakshani M, Lukow T, Liesack W. Novel bacterial lineages at the (sub)division level as detected by signature nucleotide-targeted recovery of $16 \mathrm{~S}$ rRNA genes from bulk soil and rice roots of flooded rice microcosms. Appl Environ Microbiol. 2001;67(2):623-31. doi:10.1128/ AEM.67.2.623-631.2001

16. Barns SM, Delwiche CF, Palmer JD, Pace NR. Perspectives on archaeal diversity, thermophily and monophyly from environmental rRNA sequences. Proc Natl Acad Sci U S A. 1996;93(17):9188-93.

17. Fuhrman JA, McCallum K, Davis AA. Novel major archaebacterial group from marine plankton. Nature. 1992;356(6365):148-9. doi:10.1038/356148a0.

18. Lopez-Garcia P, Moreira D, Lopez-Lopez A, Rodriquez-Valera F. A novel haloarchaeal-related lineage is widely distributed in deep oceanic regions. Environ Microbiol. 2001;3(1):72-8.

19. Dawson SC, Pace NR. Novel kingdom-level eukaryotic diversity in anoxic environments. Proc Natl Acad Sci U S A. 2002;99(12):8324-9. doi:10.1073/ pnas.062169599. 
20. Le Calvez T, Burgaud G, Mahe S, Barbier G, Vandenkoornhuyse P. Fungal diversity in deep-sea hydrothermal ecosystems. Appl Environ Microbiol. 2009;75(20):6415-21. doi:10.1128/AEM.00653-09.

21. Slapeta J, Moreira D, Lopez-Garcia P. The extent of protist diversity: insights from molecular ecology of freshwater eukaryotes. Proc Biol Sci. 2005;272(1576):2073-81. doi:10.1098/rspb.2005.3195.

22. Lecroq B, Lejzerowicz F, Bachar D, Christen R, Esling P, Baerlocher L, et al. Ultra-deep sequencing of foraminiferal microbarcodes unveils hidden richness of early monothalamous lineages in deep-sea sediments. Proc Natl Acad Sci U S A. 2011;108(32):13177-82. doi:10.1073/pnas.1018426108.

23. Rinke C, Schwientek P, Sczyrba A, Ivanova NN, Anderson IJ, Cheng JF, et al. Insights into the phylogeny and coding potential of microbial dark matter. Nature. 2013:499(7459):431-7. doi:10.1038/nature12352.

24. Wu D, Wu M, Halpern A, Rusch DB, Yooseph S, Frazier M, et al. Stalking the fourth domain in metagenomic data: searching for, discovering, and interpreting novel, deep branches in marker gene phylogenetic trees. PLoS One. 2011;6(3):e18011. doi:10.1371/journal.pone.0018011.

25. Philippe $\mathrm{N}$, Legendre M, Doutre $\mathrm{G}$, Coute $\mathrm{Y}$, Poirot $\mathrm{O}$, Lescot $\mathrm{M}$, et al. Pandoraviruses: amoeba viruses with genomes up to $2.5 \mathrm{Mb}$ reaching that of parasitic eukaryotes. Science. 2013;341(6143):281-6. doi:10.1126/ science.1239181.

26. Narasingarao P, Podell S, Ugalde JA, Brochier-Armanet C, Emerson JB, Brocks $J$ J, et al. De novo metagenomic assembly reveals abundant novel major lineage of Archaea in hypersaline microbial communities. ISME J. 2012;6(1):81-93. doi:10.1038/ismej.2011.78.

27. Sunagawa S, Mende DR, Zeller G, Izquierdo-Carrasco F, Berger SA, Kultima $J R$, et al. Metagenomic species profiling using universal phylogenetic marker genes. Nat Methods. 2013;10(12):1196-9. doi:10.1038/nmeth.2693.

28. Nielsen HB, Almeida M, Juncker AS, Rasmussen S, Li J, Sunagawa S, et al. Identification and assembly of genomes and genetic elements in complex metagenomic samples without using reference genomes. Nat Biotechnol. 2014;32(8):822-8. doi:10.1038/nbt.2939.

29. Kurokawa K, Itoh T, Kuwahara T, Oshima K, Toh H, Toyoda A, et al. Comparative metagenomics revealed commonly enriched gene sets in human gut microbiomes. DNA Res. 2007;14(4):169-81. doi:10.1093/dnares/ dsm018.

30. Qin J, Li R, Raes J, Arumugam M, Burgdorf KS, Manichanh C, et al. A human gut microbial gene catalogue established by metagenomic sequencing. Nature. 2010;464(7285):59-65. doi:10.1038/nature08821.

31. Arumugam M, Raes J, Pelletier E, Le Paslier D, Yamada T, Mende DR, et al. Enterotypes of the human gut microbiome. Nature. 2011;473(7346):174-80. doi:10.1038/nature09944.

32. Lynch MD, Bartram AK, Neufeld JD. Targeted recovery of novel phylogenetic diversity from next-generation sequence data. ISME J. 2012;6(11):2067-77. doi:10.1038/ismej.2012.50.

33. Alvarez-Ponce D, Lopez P, Bapteste E, McInerney JO. Gene similarity networks provide tools for understanding eukaryote origins and evolution. Proc Natl Acad Sci U S A. 2013;110(17):E1594-603. doi:10.1073/ pnas.1211371110.

34. Wu M, Eisen JA. A simple, fast, and accurate method of phylogenomic inference. Genome Biol. 2008;9(10):R151. doi:10.1186/gb-2008-9-10-r151.

35. Wu D, Jospin G, Eisen JA. Systematic identification of gene families for use as "markers" for phylogenetic and phylogeny-driven ecological studies of bacteria and archaea and their major subgroups. PLoS One. 2013:8(10):e77033. doi:10.1371/journal.pone.0077033.

36. Meyer F, Paarmann D, D'Souza M, Olson R, Glass EM, Kubal M, et al. The metagenomics RAST server - a public resource for the automatic phylogenetic and functional analysis of metagenomes. BMC Bioinformatics. 2008;9:386. doi:10.1186/1471-2105-9-386

37. Haggerty LS, Jachiet PA, Hanage WP, Fitzpatrick DA, Lopez P, O'Connell MJ, et al. A pluralistic account of homology: adapting the models to the data. Mol Biol Evol. 2014;31(3):501-16. doi:10.1093/molbev/mst228.

38. Caporaso JG, Kuczynski J, Stombaugh J, Bittinger K, Bushman FD, Costello EK, et al. QIIME allows analysis of high-throughput community sequencing data. Nat Methods. 2010;7(5):335-6. doi:10.1038/nmeth.f.303.

39. Martin DP, Lemey $P$, Lott M, Moulton $V$, Posada D, Lefeuvre P. RDP3: a flexible and fast computer program for analyzing recombination. Bioinformatics. 2010;26(19):2462-3. doi:10.1093/bioinformatics/btq467.

40. Castresana J. Selection of conserved blocks from multiple alignments for their use in phylogenetic analysis. Mol Biol Evol. 2000;17(4):540-52.
41. Lapointe FJ, Lopez P, Boucher Y, Koenig J, Bapteste E. Clanistics: a multilevel perspective for harvesting unrooted gene trees. Trends Microbiol. 2010;18(8):341-7. doi:10.1016/j.tim.2010.03.009.

42. Ciccarelli FD, Doerks T, von Mering C, Creevey CJ, Snel B, Bork P. Toward automatic reconstruction of a highly resolved tree of life. Science. 2006;311(5765):1283-7. doi:10.1126/science.1123061.

43. Williams TA, Embley TM, Heinz E. Informational gene phylogenies do not support a fourth domain of life for nucleocytoplasmic large DNA viruses. PLoS One. 2011;6(6):e21080. doi:10.1371/journal.pone.0021080.

44. Nasir A, Kim KM, Caetano-Anolles G. Giant viruses coexisted with the cellular ancestors and represent a distinct supergroup along with superkingdoms Archaea, Bacteria and Eukarya. BMC Evol Biol. 2012;12:156. doi:10.1186/1471-2148-12-156.

45. Woese CR, Fox GE. Phylogenetic structure of the prokaryotic domain: the primary kingdoms. Proc Natl Acad Sci U S A. 1977;74(11):5088-90.

46. Noguchi H, Taniguchi T, Itoh T. MetaGeneAnnotator: detecting speciesspecific patterns of ribosomal binding site for precise gene prediction in anonymous prokaryotic and phage genomes. DNA Res. 2008;15(6):387-96. doi:10.1093/dnares/dsn027.

47. Beauregard-Racine J, Bicep C, Schliep K, Lopez P, Lapointe FJ, Bapteste E. Of woods and webs: possible alternatives to the tree of life for studying genomic fluidity in E. coli. Biol Direct. 2011;6:39; discussion doi:10.1186/ 1745-6150-6-39.

48. Leskovec J, Lang KJ, Dasgupta A, Mahoney MW. Statistical properties of community structure in large social and information networks. 17th international conference on World Wide Web.; Beijing, China2008. p. 695-704.

49. Makino K, Uno T. New Algorithms for Enumerating All Maximal Cliques. In: Hagerup T, Katajainen J, editors. Algorithm Theory - SWAT 2004. Humlebaek, Denmark: Springer; 2004. p. 260-72.

50. Edgar RC. MUSCLE: multiple sequence alignment with high accuracy and high throughput. Nucleic Acids Res. 2004;32(5):1792-7. doi:10.1093/nar/ gkh340.

51. Yang Z. PAML 4: phylogenetic analysis by maximum likelihood. Mol Biol Evol. 2007;24(8):1586-91. doi:10.1093/molbev/msm088.

52. Yang Z, Nielsen R. Estimating synonymous and nonsynonymous substitution rates under realistic evolutionary models. Mol Biol Evol. 2000:17(1):32-43.

53. Guindon S, Dufayard JF, Lefort V, Anisimova M, Hordijk W, Gascuel O. New algorithms and methods to estimate maximum-likelihood phylogenies: assessing the performance of PhyML 3.0. Syst Biol. 2010;59(3):307-21. doi:10.1093/sysbio/syq010.

\section{Submit your next manuscript to BioMed Central and take full advantage of:}

- Convenient online submission

- Thorough peer review

- No space constraints or color figure charges

- Immediate publication on acceptance

- Inclusion in PubMed, CAS, Scopus and Google Scholar

- Research which is freely available for redistribution 